\title{
Do abjeto ao não-enlutável: o problema da inteligibilidade na filosofia de Butler
}

From the abject to the ungrievable: the problem of intelligibility in Butler's

philosophy

\section{Carla Rodrigues e Paula Gruman}

\section{(2) OpenEdition}

\section{Journals}

Edição electrónica

URL: https://journals.openedition.org/aa/8933

DOI: 10.4000/aa.8933

ISSN: 2357-738X

Editora

Programa de Pós-Graduação em Antropologia Social (UnB)

Edição impressa

Paginação: 67-84

ISSN: 0102-4302

\section{Refêrencia eletrónica}

Carla Rodrigues e Paula Gruman, «Do abjeto ao não-enlutável: o problema da inteligibilidade na filosofia de Butler», Anuário Antropológico [Online], v.46 n.3 | 2021, posto online no dia 28 setembro 2021, consultado o 14 fevereiro 2022. URL: http://journals.openedition.org/aa/8933 ; DOI: https:// doi.org/10.4000/aa.8933

\section{(c) (i) (9)}

Anuário Antropológico is licensed under a Creative Commons Atribuição-Uso Não-Comercial-Proibição de realização de Obras Derivadas 4.0 International. 


\section{Anuário Antropológico}

v.46 n.3 | 2021

2021/v.46 n.3

\section{Do abjeto ao não-enlutável: o problema da inteligibilidade na filosofia de Butler}

From the abject to the ungrievable: the problem of intelligibility in Butler's

philosophy

\section{Carla Rodrigues e Paula Gruman}

\section{(2) OpenEdition \\ Journals}

\section{Edição electrônica}

URL: http://journals.openedition.org/aa/8933

DOI: $10.4000 / a a .8933$

ISSN: 2357-738X

\section{Editora}

Programa de Pós-Graduação em Antropologia Social (UnB)

\section{Referência eletrônica}

Carla Rodrigues e Paula Gruman, «Do abjeto ao não-enlutável: o problema da inteligibilidade na filosofia de Butler», Anuário Antropológico [Online], v.46 n.3 | 2021. URL: http://journals.openedition. org/aa/8933; DOI: https://doi.org/10.4000/aa.8933

\section{(9) $(9 \Theta \Theta$}

Anuário Antropológico is licensed under a Creative Commons. Atribuição-SemDerivações-SemDerivados CC BY-NC-ND 


\section{Do abjeto ao não-enlutável: o problema da inteligibilidade na filosofia de Butler ${ }^{1}$}

From the abject to the ungrievable: the problem of intelligibility in Butler's philosophy

DOI: https://doi.org/10.4000/aa.8933

\section{Carla Rodrigues}

Universidade Federal do Rio de Janeiro, Instituto de Filosofia e Ciências Sociais, Departamento de Filosofia, Rio de Janeiro, RJ - Brasil

Professora de Ética no Departamento de Filosofia da UFRJ. Pesquisadora no Programa de Pós-Graduação de Filosofia do Instituto de Filosofia e Ciências Humanas e bolsista de produtividade da Faperj.

\section{Paula Gruman}

Université de Paris, École Doctorale - Recherche en Psychanalyse et Psychopathologie, Paris - França

Psicóloga clínica. Graduada em Psicologia pela UFRGS, mestre em Psicanálise e Pesquisa Interdisciplinar pela Université de Paris e doutoranda em Psicanálise e Psicopatologia pela Université de Paris.

Neste trabalho, o conceito de abjeto, tal como pensado por Judith Butler a partir da obra de Julia Kristeva, é analisado e aproximado da ideia butleriana de uma distinção existente entre vidas passíveis de enlutamento e vidas não-enlutáveis. Propomos uma compreensão do conceito de abjeto na obra dessas autoras, além de estabelecer uma relação entre a noção de abjeto e a ideia de impureza da antropóloga Mary Douglas. Entendemos que, na obra de Butler, existem aproximações possíveis entre as divisões entre sujeito e abjeto e entre enlutável e não enlutável. Sugerimos que a categoria da inteligibilidade é o operador teórico que atravessa esses dois momentos da obra de Butler. Compreendemos que, por mais que a ênfase da filósofa mude do gênero para a violência contra as vidas, seu interesse principal mantém-se em realizar uma crítica da norma que categoriza algumas vidas e corpos como válidos, enquanto outros pertencem a uma zona de ininteligibilidade, abjetos, cujas vidas não contam.

Butler. Abjeção. Luto, não enlutável. Inteligibilidade.
In this paper, the concept of abject, as thought of by Judith Butler based on the works of Julia Kristeva, is analyzed, and compared to the idea by Butler of an existing distinction between grievable and ungrievable lives. The concept of abject in their works is also brought to light in relation to the notion of impurity in the work of anthropologist Mary Douglas. We propose that, in Butler's theory, there are some similarities to the division between subjects and abjects, and that between grievable and ungrievable. We suggest the category of intelligibility as the element that is present throughout these two moments of her philosophy. Even if Butler's emphasis has changed, from gender to the violence against life, her main interest remains the critique of the norm that categorizes some lives and bodies as valid, while others seem to belong to a territory of unintelligibility: the abjects, whose lives do not matter.

Keywords: Butler. Abjection. Grief. Ungrievable. Intelligibility. 
O discurso somente parecerá sustentável sob a condição de se confrontar incessantemente com esse exterior, peso repelente e repelido, memória profunda, inacessivel e intima: o abjeto.

Julia Kristeva ${ }^{2}$

\section{Introdução}

Era o início dos anos 2000 quando a filósofa Judith Butler publicou Antigone's claim: kinship between life and death, aqui traduzido por O clamor de Antigona: parentesco entre a vida e a morte (Butler, 2000 [2014]). Entre os muitos aspectos importantes do livro, destacamos, para os propósitos deste artigo, o uso da noção de abjeção para a autora se referir às formas de vidas que estão apartadas da esfera social, habitando zonas de margem, de fronteira, áreas de exclusão onde o que se oferece são formas cotidianas de reiterar a ausência de inteligibilidade social e cultural. Desde os anos 1990, Butler vinha associando o tema da abjeção à esfera da não inteligibilidade, principalmente com recurso à psicanalista Julia Kristeva, como procuraremos expor na primeira parte deste artigo.

Se destacamos, desde a introdução, a importância de Antígona - tanto o livro de Butler quanto a personagem de Sófocles - é por acreditarmos que é ali neste ponto em que Butler faz convergir abjeção, inteligibilidade e direito ao luto. Este é o percurso que nosso artigo pretende percorrer: começamos com o desenvolvimento e o uso da noção de abjeção em Butler, dando um passo atrás para trazer a teoria psicanalítica à qual a filósofa recorre. Seguimos em direção ao luto e à condição de enlutável como aquilo que marca a permanência do problema ético-político de manejo destas vidas como excedentes, não-integráveis, cujas existências são enquadradas como sem valor, seja de cuidado com as vidas, seja na condição de não-enlutável das vidas perdidas, o que nos leva a pensar que Butler fará do desprezo pelos mortos o sintoma mais evidente do problema da inteligibilidade/ ininteligibilidade de certas formas de vida.

\section{Abjeção e os poderes do horror}

A abjeção, conceito pensado primeiramente pela psicanalista francesa Julia Kristeva em Pouvoirs de l'horreur (1980), foi retomada por Judith Butler em seu Gender trouble, de 1990. Ainda que tenha se mostrado crítica da abordagem teórica que Kristeva desenvolve em sua psicanálise (essencialista, heterocêntrica e exercendo uma colagem entre feminino e maternal, segundo Butler), a filósofa estadunidense retoma seu conceito de abjeção a fim de pensar os gêneros e sexualidades fora da norma. Butler aplica o conceito de abjeção às existências que não se encaixam nos parâmetros normativos heterossexuais, retomando seu caráter fronteiriço, de exclusão. "É pelo viés da abjeção que Butler inaugura o debate acerca da vulnerabilidade das pessoas transexuais, travestis, transgêneros e intersexos em função
1 Este artigo é parte integrante da pesquisa "Judith Butler: do gênero à violência de Estado", projeto realizado no âmbito do edital E-03/201, Jovem Cientista do Nosso Estado, Faperj (2018/2021).

2 Kristeva, 1980, p. 14. Sempre que a referência for a uma edição que não seja a brasileira, as traduções são nossas. 
das normas de gênero" (Porchat, 2015, p. 40).

Kristeva (1980) define a abjeção como o movimento que traça as fronteiras entre o eu e o outro, uma exclusão constituinte. O sujeito funda-se no mesmo movimento em que torna abjeto algo de si, de modo que o abjeto tem suas origens no sujeito: ele é parte do grupo, cultura, sujeito ou mecanismo do qual é rejeitado. O abjeto é assim reconhecido como um elemento intolerável, algo que participa da constituição do "eu" para tornar-se "não-eu". Essa característica do abjeto que faz com que o pensemos como um excluído paradoxal. Interno ao sujeito, torna-se externo pelo movimento mesmo de sua expulsão, rejeição, sujeição. Concomitantemente, o próprio sujeito se fabrica e se produz por meio desse expulsar constituinte. Para tornar-se sujeito, torna-se necessário produzir um "eu”, uma identidade inteligível face a uma norma, que exige o movimento de expulsar o elemento percebido como intolerável: o abjeto. Assim, é na exclusão do que é considerado inaceitável, nesse repúdio do abjeto, que originalmente era parte do eu, que se produz a fronteira que separa o sujeito do abjeto.

Para Kristeva (1980), a relação entre esses dois polos é dialética: um não existe sem o outro. Não existe identificação inteligível possível sem um campo de identificações impossíveis. Ao mesmo tempo em que o sujeito se fabrica tornando-se aceitável conforme certas normas, leis e discursos, um outro domínio se cria, aquele da abjeção. $\mathrm{O}$ abjeto representa as existências que foram consideradas aquém da sujeição. $O$ estatuto de sujeitos lhes é negado, restando a essa existência permanecer do lado ininteligível da fronteira que separa o inteligível do ininteligível.

A riqueza do conceito de abjeção reside na compreensão de que é na criação do abjeto que se funda essa fronteira, de forma que o abjeto, ainda que de forma aparentemente contraditória, é a própria demarcação, o elemento que funda o limite, e vive para além dessa fronteira. É fundamental notar que, na dialética sujeição-abjeção, o abjeto é necessariamente contingente. Isto é, não tem estatuto ontológico, essência determinada ou características que o definem de forma transcendental e imutável, pois existe apenas em sua relação com o sujeito e com os parâmetros de subjetivação aceitos, aos quais tanto sujeitos quanto abjetos estão submetidos. Kristeva (1980) observa que a abjeção pode se referir aos mais diversos temas. Para compreendê-la, é interessante pensar no modelo proposto pela autora, que apresenta a abjeção como intrinsecamente humana e primitiva, presente desde os momentos mais arcaicos da constituição psíquica. Para isso, a autora se vale do paradigma do bebê para apresentar um modelo para a abjeção, tomando o corpo humano em sua experiência de dependência inicial em relação ao cuidado do outro (com nenhuma separação existente ainda entre eu e cuidadores, interno e externo ou sujeitos e objetos) ${ }^{3}$. Segundo a psicanalista, numa inicial indiferenciação entre o bebê e seu entorno, na experiência das pulsões desintegradas e do corpo ainda fragmentado do bebê, atravessa-se a expulsão daquilo que é rejeitado por ele: o vômito, a urina, as fezes.

Tomando a náusea como exemplo, Kristeva (1980) caracteriza um mal-estar difuso e intenso do bebê, cujo corpo identifica um conteúdo considerado insupor-
3 Em Butler, o bebê que precisa de cuidados para sobreviver se tornará, principalmente a partir de 2009, ano da publicação de Frames of war, paradigma da nossa condição de interdependência radical. 
tável como não-eu. Dentro dos parâmetros do eu, o insuportável do conteúdo faz com que este precise ser expulso. Assim, ele é expelido, rechaçado, rejeitado pelo eu. Entretanto, esse conteúdo a ser expulso não é "outro" para o eu, de forma que também o eu é expelido e repudiado. No mesmo movimento em que a expulsão de um conteúdo funda os limites do sujeito, também algo do sujeito é expulso: sua parte, agora, percebida como abjeta. Na origem da constituição psíquica, haveria então não apenas uma expulsão, mas uma perda relativa a uma parte do eu: “[...] assim, eles veem que eu estou me tornando um outro ao preço de minha própria morte" (Kristeva, 1980, p. 11).

Ressaltamos que Kristeva expande o conceito de abjeção e passa a se referir a diversos movimentos que vão muito além do psiquismo individual, utilizando-o para pensar representações e fenômenos artísticos, simbólicos, culturais e coletivos. É o abjeto para um sistema simbólico que interessa à psicanalista, assim como será a abjeção e sua relação com a medida de inteligibilidade de certas vidas que interessará a Butler. O resto, o descartado que é o abjeto, sinaliza constantemente o que se rejeita em si mesmo para ser sujeito e poder existir em dado sistema simbólico.

Inicialmente tão interno ao bebê que constitui uma parte sua, inseparável do bebê e de sua experiência física e subjetiva, o conteúdo considerado intolerável, agora rejeitado, é reconhecido como não-eu. Ao passo em que o rechaçado é identificado como não-parte de mim, as bordas que me fazem estão mais nítidas. Agora o eu reconhece-se numa identificação pelo negativo: eu não sou o que eu rejeitei, o que eu lanço para fora de mim. Nascido nas origens mesmas do eu/sujeito, no exemplo dado, as do bebê, o conteúdo intolerável só é reconhecível como diferente dele, e só se produz como diferente, quando do ato de sua abjeção. De tal forma, constitui-se a exclusão como movimento constitutivo e delineante, separando eu e outro. Por existir como elemento separado e definido - identificado e identificável somente a partir do momento em que se descola do eu e torna-se algo separado -, podemos entender que o abjeto pode construir-se, fabricar-se apenas dentro de um determinado esquema, com seus parâmetros de tolerável/ intolerável.

Se o fundamento teórico da abjeção é um paradigma corporal, lembramos que não é por isso que ela se faz menos psíquica. Sobretudo, para Kristeva, é o caráter linguageiro da abjeção que se faz objeto de interesse. Nem sujeito nem objeto, o abjeto se produz como um outro com o qual identificar-se é impossível, visto que sua existência mesma se produz pelo movimento da rejeição. Inassimilável, o abjeto pode surgir do interior de um sistema (corpo, coletivo, psiquismo), mas seu caráter intolerável faz com que seja ameaçador, precise ser expulso, e seja mobilizado a fim de estabelecer a distinção entre dentro/fora da norma.

Não confundido com o objeto, Kristeva (1980) frisa que o abjeto não é um correlato do sujeito, seu complemento ou antítese, cuja obtenção ou incorporação traria uma completude ou equilíbrio utópico. $\mathrm{O}$ abjeto compartilha com o objeto uma única característica, a de se opor ao eu. Trata-se de um outro radical que desafia constantemente o sujeito, ameaçando-o com a ausência de sentido. 
É o que fará a autora dizer: "Para cada Eu, seu objeto, para cada Supra-Eu, seu abjeto" (Kristeva, 1980, p. 10). O abjeto seria algo de altamente repugnante, que o eu percebe de forma intensa como não-eu, mas que ao mesmo tempo constitui o eu, o que leva à internalização do horror a si mesmo. Trata-se de algo que eu reconheço o suficiente para rejeitar massivamente, ao mesmo tempo em que sua característica abjeta o torna um peso obscuro e sem-sentido.

A desgraça absoluta de reconhecer o abjeto está em que o sujeito perceba que esse impossível-de-se-dizer, esse intolerável, irrepresentável, inassimilável e rechaçado, abjeto é, originalmente, uma parte do sujeito, do eu e, afinal, do próprio sistema simbólico. É o fato de que todas outras relações, objetos e construções do eu se fundam na perda inaugural e fundamental que produz esse sujeito, ou seja, a abjeção. A perda, o rejeitar pelo sujeito (de parte de si mesmo) que é a abjeção, torna-a ainda mais intolerável. $\mathrm{O}$ abjeto me lembra do que eu tenho de perder para ser sujeito. Movimento original à fundação do sujeito, a abjeção ex-pulsa: entorna o sujeito de abjeto, sem que ele ainda tenha podido se diferenciar de seus objetos. Antes mesmo que ele possa ser e significar, ele é confrontado com o impossível da existência. Assim, a abjeção nos indica os limites do humano. Tamanho é o caráter aterrador do abjeto para o sujeito da norma que sua reincorporação equivaleria ao aniquilamento do sujeito. Frequentemente relacionado ao sujo, ao podre e, mesmo, à morte, Kristeva dirá sobre o abjeto: “Não é então a falta de limpeza ou de saúde que faz o abjeto, mas aquilo que perturba uma identidade, um sistema, uma ordem. Aquilo que não respeita os limites, os lugares, as regras. O entre-dois, o ambíguo, o misto" (Kristeva, 1980, p. 12).

Contingencial e situacionista, o rejeitado só existe a partir de algo de que se separa. O abjeto não se interessa em saber "quem" ou "o quê" é, mas por "onde”. “Onde se situa minha existência?" (Kristeva, 1980). Fora da norma, para além da margem. Ainda assim, na borda, ao mesmo tempo: ser-fronteira, habitante da fronteira e estrangeiro. Aquilo que é rejeitado não para de delimitar o seu universo. Suas barreiras são fluidas, suas margens se deslocam, porque se constituem num movimento que é sempre contingencial, dependente da norma (simbólica) e/ou do sujeito. "Porque, enquanto demarca, ela não separa radicalmente o sujeito daquilo que o ameaça - ao contrário, denuncia seu perigo perpétuo”, argumenta Kristeva (1980, p. 17).

Ora, um dos interesses de pensar o conceito de abjeto pode ser justamente para encontrar nele uma possibilidade política. Se o abjeto é ameaçador para a norma e seus sujeitos, que desdobramentos podemos depreender disso? É possível pensar o aspecto de resto, rechaçado, como um ponto, inesperadamente, potente para um repensar dos parâmetros normativos e, mesmo, da própria norma? Antes de procurarmos respostas na leitura de Butler, vamos à antropologia de Mary Douglas e aos perigos da impureza.

\section{O abjeto como impuro: Mary Douglas antes de Kristeva}

Em seu Pouvoirs de l’horreur, de 1980, referindo-se a Mary Douglas, Julia Kris- 
teva diz que cada sociedade, por meio de seus ritos de purificação, promove a exclusão da sujeira para, assim, fundar o "limpo", o puro, de cada grupo social - ou mesmo de cada sujeito. É ao ser excluída como objeto possível, ao ser vista como não-desejável e, Kristeva dirá, ao ser abominada como abjeta, que a sujeira vira mácula e funda a ordem do limpo e do sagrado. Para Kristeva (1980), essa impureza é o que escapa ao sistema simbólico, à racionalidade social, à lógica de uma sociedade - e é a sua exclusão que contribui para a constituição de uma estrutura. A psicanalista considera que Mary Douglas viu no corpo humano o protótipo desse ser translúcido que é a sociedade-sistema simbólico (Kristeva, 1980).

Mary Douglas, em seu Pureza e perigo, de 1966 - antes, portanto, das formulações de Kristeva (1980) e Butler (1990, 1993) - traz a ideia de alguns binômios opositores, como limpeza/sujeira, ordem/desordem, pureza/impureza. Em Douglas, esses opostos são apresentados com o intuito de pensar a constituição dos limites, internos e externos, de um corpo ou de uma sociedade. Não é por acaso, então, que o estudo do abjeto remete à sua obra, tanto pela natureza do abjeto alvo de um repúdio fundamental e estruturante - quanto pela própria ideia de constituição de uma ordem social a partir de delimitações, fronteiras, que separam o aceitável do inaceitável e que são sempre dependentes das contingências.

O sujo, para Douglas (1966), sempre remete à desordem. Mas não há uma ontologia do sujo, tampouco do rejeitável, do impuro, do desprezível: o inaceitável está nos olhos de quem vê. Impossível aqui não pensar no aspecto contingencial da norma, tal qual pensada por Butler (1990, 1993). Além disso, para Douglas (1966), o que é sujo atenta contra a ordem, e a tentativa de um sistema social de eliminá-lo relaciona-se a um esforço por trazer ordem ao que nos cerca ${ }^{4}$. Para haver ordem, precisam existir limites, bordas, que separem o aceitável (limpo, puro) do inaceitável (sujo, impuro). A transgressão desses limites deve ser apresentada e reiterada como perigosa, de modo que a transgressão dessa fronteira seja ameaçadora e possa sustentar a ordem do que é visto como puro e que, assim, é aceito. A moralidade está atrelada à constituição desses limites, de modo que aquilo que é sujo é ruim ou errado, é nojento, podre e deve estar do lado de fora de um sistema social. As ideias do que é puro ou impuro estão sempre em transformação, pois dependem dos valores de uma dada sociedade.

Assim, é o impulso à ordem que cria e recria essas separações entre puro e impuro (sujeito e abjeto, em Kristeva e Butler), que vão mudando dependendo das contingências sociais e culturais, sem que deixe de existir essa oposição. As margens (corporais e sociais) estão muito carregadas de poder - porque podem definir o que é interno e o que é externo (Douglas, 1966). Na visão de Douglas (1966), aquilo que uma dada sociedade considera limpo ou podre é simbólico da relação entre partes de tal sociedade, podendo operar como um espelhamento de hierarquias ou simetrias. Recordemos que sujeira não é uma característica que se define por si só, ela é aquilo que vem de um transpor de limites, que surge do outro lado de uma margem. E o que é das margens (do corpo, do social) representa a fragilidade da ordem simbólica (Kristeva, 1980).

Lembremos que as sociedades têm limites externos, bordas e uma estrutura
4 A ideia de impureza no abjeto torna interessante referir ao texto de Berenice Bento (2021) sobre a abjeção e a feiura. Beleza ou feiura seriam hierarquias internas a categorias inteligíveis. Bento aborda como a noção de abjeto, ali utilizada para pensar população trans e travesti na norma heterossexual, ultrapassa a ideia de oposições como belo e feio e se relaciona mais com a negação da própria inteligibilidade. 
interna. Se orifícios corporais são frequentemente vistos como impuros (e aqui diremos, abjetos), isso se relaciona, para Douglas, ao fato de serem marginais - os orifícios estão nas bordas do corpo, tudo o que entra e que sai o faz por essas fronteiras. O nojo do marginal teria a ver então com a sensação de caos que poderia advir de um sistema que perdeu sua ordem: o que é nós e o que é o outro não está claro. Emprestando o termo de Kristeva (1980) e Butler (1990, 1993), é abjeto aquilo que ameaça por borrar esses limites, por ser o próprio limite ou seu habitante. Sobre as margens, Mary Douglas diz:

(...) todas as margens são perigosas. Se as levamos para lá ou para cá alteramos o formato da experiência fundamental. Toda estrutura de ideias é vulnerável em suas margens. É esperado que os orifícios do corpo simbolizem seus pontos especialmente vulneráveis. A matéria que sai deles é a forma mais óbvia de algo marginal. Saliva, sangue, leite, urina, fezes ou lágrimas simplesmente serem emitidos para fora atravessam o limite do corpo. (...) O erro está em tratar as margens do corpo isoladamente de outras margens. Não há razão para presumir que a atitude do indivíduo com seu próprio corpo e com sua experiência emocional tenha primazia em relação à sua experiência cultural e social (Douglas, 1966, p. 122).

Poderíamos pensar aqui no abjeto como excluído paradoxal de um sistema normativo. Ele é rejeitado por remeter ao impuro e desordeiro, contudo é no movimento de expulsar o abjeto que se fundam as barreiras que separam o admissível do inadmissível - fronteiras habitadas pelo abjeto.

Para entender o que se entende como corporalmente sujo, precisamos poder reconhecer o que é entendido como perigoso para uma sociedade. Cada cultura - e norma - tem suas próprias noções de sujeira e podridão, que são contrastadas com suas noções do que é válido e que deve ser reconhecido, aceito. Para Douglas (1966), o simbolismo do corpo é utilizado para expressar o medo de ter fronteiras invadidas e o perigo da transgressão. Os rituais de limpeza, cujo objetivo é aniquilar o abjeto, são uma tentativa de criar e manter uma cultura em específico, um conjunto de valores (morais) e uma identidade social e cultural compreensível, aceita e estável. Purificar-se da sujeira é purificar-se do abjeto e, assim, ser aceito e inteligível (dentro da norma de uma dada sociedade).

Reconhecemos o impuro (abjeto) como uma ameaça à ordem e o rejeitamos. Nesse processo, ele mostra ter uma identidade, ele é visto como o indesejável e é perigoso. Se Douglas (1966) fala aqui em matéria corporal, lembremos que para ela o corpo espelha a sociedade (e vice-versa) e mantenhamos em mente a ideia do abjeto para a norma. O abjeto é ameaçador enquanto tiver uma identidade reconhecível como impura. O que é percebido como sujo vai sendo fabricado em um processo de criar uma ordem. Existe um perigo - e, por essa razão, um poder - na transgressão de limites implícita no aspecto marginal do abjeto. A pureza tenta se manter com uma identidade estável e sem ambiguidade (Douglas, 1966), ela tenta ter uma forma fixa. Tentar alcançar uma identidade válida e pura 
é tentar nos forçar a uma experiência sem contradição - sem abjeto no sujeito, nem sujeito no abjeto.

Notemos que Douglas não é a única a frisar a existência de uma relação entre o que se considera eticamente errado e o que se considera nojento ou repulsivo. Se considerarmos a questão da abjeção como aquilo que é visto como repudiável por ser inadmissível ou ininteligível dentro de uma norma, veremos reflexos das ideias de Aurel Kolnai (1929) em nossas reflexões sobre sujeito e abjeto. Aquilo que é moralmente desprezível, para esse filósofo, é repulsivo, nojento. O nojo e desprezo não são somente físicos, eles são também provenientes de qualidades morais (Kolnai, 1929). Essa ideia reforça a noção de que existe uma relação entre abjeção e norma social. A impureza se relaciona aos limites, à margem de uma ordem. A impureza seria uma das formas possíveis da abjeção, para um conjunto social (Kristeva, 1980). A abjeção, assim, faz parte da ordem social e simbólica, em nível individual e coletivo. Por isso, o fenômeno do abjeto seria universal, por aparecer em toda sociedade ou civilização, ainda que em diferentes formas.

\section{O problema da abjeção em Butler}

Assim como Mary Douglas e Julia Kristeva, também Judith Butler vê no abjeto uma possibilidade de "torção", isto é, de um certo reapropriar-se do que é rechaçado pela norma para poder enfrentá-la ${ }^{5}$. Butler, por outro lado, propõe de forma crítica a retomada de uma certa queerness, ainda que reconhecendo os limites dessa abordagem (Butler, 1993). Em Gender trouble (1990), Butler aplica o conceito de abjeto a partir de sua teoria sobre a matriz heteronormativa. Entendendo norma a partir do modelo foucaultiano em "História da Sexualidade I" (1976) - ou seja, como inerentemente interna ao sujeito, produto e produtora de subjetividade, composta em uma trama difusa de saberes, práticas e relações de poder -, Butler indica que a heteronormatividade regula nossas ações, práticas, subjetividades e desejos.

É por meio da performatividade de uma estilística de gênero reiterada e iterável que os gêneros binários e a heterossexualidade compulsória se fundam como pressuposto necessário para vidas inteligíveis. As identidades dos sujeitos seriam produzidas em práticas regulatórias do gênero. A identidade estaria mais no campo de um ideal normativo do que de uma real descrição da experiência vivida. As normas que regulam o gênero regulam também as possibilidades consideradas válidas, isto é, inteligíveis, de ser sujeito e ter uma identidade. Essa última, para Butler, se produz por normas de inteligibilidade que são socialmente instituídas a partir da exigência da coerência entre sexo/gênero/desejo e mantidas no âmbito da heteronormatividade. Os sujeitos que não conseguem se integrar nessa matriz de sentidos que dita o que é compreensível, significável e representável ficam relegados ao campo da ininteligibilidade. No domínio do ininteligível, o próprio estatuto de pessoa torna-se questionável (Butler, 1990).

A relação entre sujeito e abjeto aparece em Butler em conjunto com a relação entre inteligível/ininteligível. O ininteligível é relacionado ao abjeto, enquanto o
5 Consideramos que uma das características da obra de Butler é ser multidisciplinar e, portanto, dialogar para além do campo filosófico stricto senso. Principalmente em suas obras iniciais, a interlocução com a Antropologia é significativa, notadamente a influência de Gayle Rubin (2017) nas formulações de Gender trouble ou mesmo a relevância do conceito de impuro, em Mary Douglas, no debate sobre abjeção, assim como as referências a Marilyn Strathern (2009) em O clamor de Antígona e suas críticas ao estruturalismo de Lévi-Strauss. No entanto, se aqui privilegiamos a interlocução com Kristeva é por reconhecermos que a teoria psicanalítica tem sido instrumento principal e constante nas formulações políticas de Butler. A este respeito, permitimo-nos referir a Rodrigues, 2019; 2021. 
inteligível aparece aproximado do sujeito, da existência válida e compreensível face à norma. "Gêneros 'inteligíveis' são aqueles que de alguma forma instituem e mantêm relações de coerência e continuidade entre sexo, gênero, prática sexual e desejo" (Butler, 1990, p. 23). Aquilo que é inteligível só o é em relação a uma norma. Para que exista uma inteligibilidade, é necessário que haja também um ininteligível, visto que o inteligível se constrói e se torna compreensível por meio da rejeição e da recusa de identificação com o que é ininteligível.

Se tomarmos o exemplo da homossexualidade, Butler a entende como culturalmente ininteligível. Assim, ela é excluída, entendida como fora da norma e igualada a uma identificação impossível para os sujeitos da heteronorma. Entretanto, deve haver uma compreensão de homossexualidade que seja minimamente representável pelos sujeitos da norma, para que, assim, possa haver uma reiterada recusa de identificação com isso que é culturalmente abjeto e, portanto, ininteligível. Dessa forma, para que a heterossexualidade possa se manter como um molde social estável, ela depende da homossexualidade para manter uma oposição permanente. De tal modo, a heterossexualidade depende da homossexualidade para existir como norma, e, dessa maneira, a homossexualidade se torna ininteligível, proibida, rejeitada e forcluída.

O que resta "impensável" e "indizível” nos termos de um molde cultural existente não é necessariamente o que é excluído da matriz de inteligibilidade dentro desse molde; ao contrário, é o marginalizado, não o excluído, a possibilidade cultural que causa terror ou, ao menos, a perda de aprovação. Não ter o reconhecimento social como um heterossexual, de fato, é perder uma identidade social possível e talvez ganhar outra que é radicalmente menos aceita. O "impensável" então está inteiramente dentro da cultura, mas inteiramente excluído da cultura dominante (Butler, 1990, p. 105).

Butler (1990) retoma Kristeva, entendendo a abjeção como uma noção estruturalista de um tabu constitutivo de limites, que, assim, desenha as bordas do sujeito pela exclusão, delineia uma norma a partir da criação do fora da norma. Na leitura butleriana de Kristeva, o abjeto é aquilo que foi expulso do corpo, descartado como excremento e transformado em "Outro". Aparentemente, trata-se de expulsar o que é estrangeiro, mas o estrangeiro se constitui como tal pela sua própria expulsão. $\mathrm{O}$ abjeto se constrói como não-eu, delineando os limites do corpo e do sujeito. A separação entre interno e externo e as bordas do corpo se desenham através da transformação em "Outro" de algo que era parte da identidade.

Para Butler (1990), a expulsão/rejeição que caracteriza a abjeção colabora para o construir e solidificar de identidades, por meio de mecanismos de dominação e exclusão. Conforme a filósofa: "A produção do insimbolizável, do indizível, do ilegível é também sempre uma estratégia de abjeção social” (Butler, 1993, p. 190). Em Gender trouble, Judith Butler traz o abjeto como aquilo que é da ordem do ininteligível como resultado de dinâmicas normativas. Nascido no coração da norma, o movimento de abjeção produz o sujeito (inteligível), ao gerar a identificação impossível, forcluída, impensável, ininteligível. Quando Butler aplica o conceito de abjeção, está interessada em pensar o modo como funciona em relação às 
categorias de gênero. Denunciando uma heteronormatividade fundacional, o abjeto seria tudo aquilo que desviaria das categorias de gênero "inteligíveis": os/as homossexuais, as lésbicas, as drag queens, travestis, trans...

É assim que Butler toma o abjeto como paradigma para pensar o gênero, tomando "o gênero não-inteligível" como ponto de referência. Se pensarmos que aquilo que é abjeto sempre o é segundo um discurso, uma norma, certos parâmetros linguageiros, simbólicos específicos, pensar nos abjetos de uma cultura, entender onde se situam, quem são, pode nos informar sobre a norma. Identificar aquilo que é impensável para a norma, afinal, define o que, para Butler, é pensável. Lembramos que aquilo que é da ordem do abjeto é sempre contingencial: ou seja, depende do sistema em que está inserido. Não há ontologia do abjeto, seus limites mudam, suas fronteiras se movem, sua definição é instável e em transformação constante, visto que é produzido no movimento mesmo da exclusão, o que pode ser lido como coerente com a ideia de identidades que se fabricam pela reiteração de atos (corporais e linguageiros) estilizados.

A força normativa da performatividade - seu poder para estabelecer o que se qualifica como "ser" - opera não apenas através da reiteração, mas através da exclusão também. E, no caso dos corpos, essas exclusões assombram a significação enquanto suas fronteiras abjetas ou enquanto aquilo que está estritamente forcluído: o invivível, o não-narrável, o traumático" (Butler, 1993, p. 188).

Importante observar que, para Butler, o campo do simbólico não é imutável, mas sempre passível de transformação. Dessa forma, o que é um sujeito inteligível ou ininteligível, válido ou abjeto, pensável ou impensável, não é uma definição eterna e transcendental. Ao contrário, o abjeto se produz nesse movimento de exclusão. De tal modo, tomar o abjeto como paradigma para pensar o gênero é empregá-lo para poder entender e analisar a norma, torná-lo um problema político, "dar direito de cidadania ao inabitável, ao "invivível”, ao Outro que virou 'merda", conforme Porchat (2007, p. 71 ), autora que nos permite fundamentar o percurso que estamos traçando do abjeto à condição de enlutável.

$\mathrm{O}$ abjeto funciona como elemento de constante questionamento das normas sociais, podendo ser um operador crítico potente para rearticular os termos da inteligibilidade do gênero. Por isso, a psicanalista chama atenção para o caráter de possível transformação que conteria o conceito de abjeto, destacando que Butler afirma "que é pela voz do "abjeto" que a reflexão sobre a produção do humano, as normas que o regulam e a possibilidade de transformação social se fará ouvir" (Porchat, 2007, p. 94).

Em Bodies that matter (traduzido no Brasil como Corpos que importam), Butler afirma: "[...] corpos apenas surgem, apenas resistem, apenas vivem dentro dos limites que produzem certos esquemas regulatórios altamente generificados" (Butler, 1993, p. 11). Se Butler se dedica à pergunta de como se fabricam, se mantêm e vivem os corpos que importam, isso não se faz sem que se coloque também a questão antípoda: como esses mesmos limites produzem, além dos corpos inteligíveis, um domínio habitado pelos corpos abjetos? Tal questionamento da filósofa faz com que se interrogue sobre a natureza mesma de tais limites, o 
constrangimento (constraints) à norma em si, produtora dos corpos pensáveis e impensáveis. Ainda que Butler se pergunte sobre quais os parâmetros e quanto à forma mesma de operar das normas de gênero, aqui nos interessamos mais na oposição entre corpos que importam e corpos cuja existência não conta: é abjeta. Impensáveis, e Butler (1993) dirá, até, invivíveis, esses corpos que habitam o domínio do ininteligível não se constituem como oposto perfeito do inteligível. Tal qual Kristeva (1980), Butler caracteriza o território do abjeto como aquilo que assombra o domínio dos corpos que contam, representando o limite do inteligível, aceitável, processável, representável.

"Interno" e "externo" somente fazem sentido se em relação a um limite que luta por estabilidade. E essa estabilidade, essa coerência, é determinada, em grande parte, por ordens culturais que validam o sujeito e forçam sua diferenciação em relação ao abjeto. Assim, "interno" e "externo" constituem uma distinção binária que estabiliza e consolida o sujeito coerente" (Butler, 1990, p. 182).

Ao conceber o gênero como performativo, a questão de identificação se torna central para Butler, para quem a normativa heterossexual estimula e valida certas identificações, ao mesmo tempo em que forclui ou interdita outras. Retomando a noção de uma relação de construção mútua entre sujeitos e abjetos, Butler (1993) caracteriza de excludente a matriz que forma sujeitos. Os excluídos seriam os abjetos, aqueles que não são sujeitos, mas que formam o exterior constituinte dos sujeitos (corpos que importam/corpos que pesam). O território das vidas impensáveis, invivíveis contorna, cerca o domínio da sujeição válida. Essa zona da abjeção seria povoada pelos corpos que representam as identificações ameaçadoras à norma.

Será por essa razão que Butler diz que o sujeito se constitui através da exclusão e da abjeção, dependendo, para existir, da constituição de um exterior abjeto. Ainda de acordo com Kristeva (1980) e com seu próprio pensamento em Gender trouble, Butler (1993) não deixa de lembrar-nos que tal abjeto, paradoxalmente, também é, originalmente, interno ao sujeito. É o repúdio do que é percebido como intolerável, e tornado abjeto, que funda o sujeito da norma, concomitantemente formando o exterior abjeto. Notamos como o caráter de fronteira do abjeto segue presente, movimento de dentro/ fora equivalente às concepções de dentro/fora da heteronorma.

Tão necessário quanto pensar como se produzem os corpos que contam, para Butler, será poder refletir quanto aos corpos que não se fabricam, que não acedem ao domínio da existência. Butler (1993) ressalta que as identificações conformes à norma demandam uma rejeição que acaba por produzir o abjeto, um domínio sem o qual não há sujeito. $O$ caráter ameaçador do abjeto persiste devido à sua característica de "espectro", representante das identificações impossíveis ${ }^{6} .0$ terror representado pelo abjeto consiste em sua própria existência, que ameaça constantemente o estatuto do sujeito, principalmente pelo seu paradoxo de ser interno ao sujeito e fruto da norma, ainda que repudiado e rejeitado por ambos. Butler (1993) propõe pensar o abjeto não como aquele domínio ao qual cabe constantemente apontar e desafiar as normas sociais, mas como um possível ponto para exercer crítica, na tentativa de questionar e repensar os próprios termos que garantem legitimidade simbólica e inteligibilidade.
6 A ideia de espectro será retomada por Butler em sua interlocução com a filosofia de Achille Mbembe. Em seu livro mais recente, Butler propõe pensar as formas de vida não integráveis a partir da experiência de um continuum de luto, existências fantasmáticas, o que dialoga com a proposição de Mbembe (2018) de vidas à sombra, assombradas, constrangidas em zonas de morte e sacrifício. 
Na norma tal qual pensada por Butler (1993), o sujeito está próximo do que é considerado uma vida que importa. Já o abjeto, enquanto aquele que não está propriamente situado nas normas de gênero, teria sua própria humanidade colocada em questão. É aqui que se situa a dualidade entre corpos que importam e corpos que pesam, que não são considerados, não são vidas que contam. A forclusão e os apagamentos que derivam de uma construção de gênero de matriz excludente fazem com que certas formas de se situar no gênero sejam incompreensíveis para dada cultura, ficando assim aproximados do inumano.

Para exemplificar a abjeção no que tange às identificações, Butler utiliza a categoria da homossexualidade como paradigma. Opondo-a à heterossexualidade, Butler retoma sua compreensão do que chamou de melancolia de gênero (em que se vale de articulações com o tema da identificação em Freud) para resgatar a noção de que a identificação heterossexual se funda no repúdio do desejo homossexual. Assim, a identidade heterossexual precisa ser fundada no ato de rejeitar e de rechaçar o vínculo homossexual. Como o gênero é compreendido como performativo por Butler, ou seja, dependente de atos reiterados, a heterossexualidade precisa constantemente rejeitar, abjetar a homossexualidade para manter-se compreensível, pensável, inteligível. É a identificação com o desejo homossexual, afinal, que leva à sua abjeção. É por isso que Butler diz que há "uma possível identificação com a homossexualidade abjeta no coração da identificação heterossexual" (1993, p. 111). A identificação com a homossexualidade abjeta precisa ser desmentida: ela é temida justamente porque, na verdade, o sujeito já a fez (isto é, já se identificou com a homossexualidade) e precisou desfazer-se de tal identificação, em uma (nova) identificação que mantém o desejo pelo mesmo sexo através da instituição de sua abjeção.

Se a identificação heterossexual acontece não através da recusa de identificar-se como homossexual, mas através de uma identificação com uma homossexualidade abjeta que deve, por assim dizer, nunca se mostrar, então nós podemos depreender que posições normativas do sujeito dependem de identificações abjetas e são articuladas através de uma região composta por essas? (Butler, 1993, p. 112).

Butler estabelece uma relação entre abjeção e o conceito psicanalítico de forclusão, dizendo que a abjeção significa rejeitar ou jogar fora e pressupõe um domínio de agência do qual está separada, propondo que "certas zonas abjetas dentro da sociabilidade também apresentam essa ameaça, constituindo zonas inabitáveis que o sujeito fantasia como ameaçadoras para sua própria integridade, trazendo a possibilidade de uma dissolução psicótica” (Butler, 1993, p. 3). Se quando Butler (1990, 1993) escreveu originalmente sobre a abjeção, a homossexualidade ocupava lugar de destaque enquanto identificação paradigmática do abjeto, hoje, poderíamos repensar esse abjeto a partir de outros lugares, como, por exemplo, transgêneros, intersexo, assexuados, não-binários...

\section{Abjeção e condição de enlutável}

Nosso interesse no uso da categoria da abjeção por Butler $(1990,1993)$ residia, 
inicialmente, na possibilidade de tomar as dissidências de gênero como paradigma para pensar a norma, entendê-la, abordá-la, compreender seu funcionamento, parâmetros, os discursos valorativos e ético-morais que a sustentam. Entretanto, também é possível avançar no tempo na obra butleriana e pensar a respeito do seu interesse na oposição entre vidas enlutáveis e vidas não-enlutáveis. Pensamos haver uma relação entre esses dois momentos da obra de Butler. Se a abjeção era majoritariamente empregada para pensar o gênero, podemos pensar - e nos unimos nisso a Kristeva e a Butler em dados momentos - que o conceito de abjeção pode servir para todo grupo social que se vê fora de uma norma, sofrendo os efeitos dessa exclusão. Com isso, Butler vai expandir os desdobramentos ético-políticos do tema da abjeção, pensando a condição de vida não-enlutável dos prisioneiros de Guantánamo, dos imigrantes, dos palestinos ${ }^{7}$ e de todos aqueles cujas vidas serão marcadas como abjetas e, portanto, ininteligíveis e não-integráveis. Estamos de volta ao livro O clamor de Antígona, apontado desde a introdução como o momento em que abjeção, inteligibilidade e direito ao luto começam a se encontrar, a partir das formulações de uma pergunta com a qual a filósofa encerra o primeiro capítulo do livro: "Que novos esquemas de inteligibilidade legitimam nossos amores, os tornam reconhecíveis, fazem de nossas perdas verdadeiras perdas?” (Butler, 2000, p. 25).

A abordagem de Butler ao problema do luto também se vale da teoria psicanalítica, sobretudo da leitura que faz de Freud. Interessa aqui segui-la na proposta de um deslizamento do luto como categoria clínica para categoria ético-política (Rodrigues, 2020). Este movimento começa depois do 11 de Setembro, quando ela propõe reflexões a respeito de como o governo dos EUA estava fazendo do luto o motor para reações violentas e discriminatórias. Ao longo dos últimos 20 anos, Butler $(2004 ; 2009 ; 2015 ; 2020)$ desenvolveu sua obra em torno do luto como um direito, como operador da distinção entre vida vivível e vida matável - separação que opera na naturalização das mortes - e sobretudo na perda como experiência de desamparo e despossesão, fundamento para o reconhecimento da nossa interdependência e da nossa responsabilidade ética: "Somos desfeitos [undoing] uns pelos outros. E se não o somos, falta algo em nós. Esse parece ser o caso com o luto, mas só porque já era o caso com o desejo", escreve Butler (2019, p. 44). Desfazer-se significaria, nesse contexto, admitir que todo "eu" é constituído pelo "não-eu" do qual tenta afastar-se.

Para articular inteligibilidade e perda, Butler recorre ao conceito de enquadramento, proposto pelo sociólogo Erwing Goffman (2012), mas não apenas ${ }^{8}$. Se até aqui a noção de abjeção estava funcionando para estabelecer limites e relações dialéticas entre inteligibilidade e ininteligibilidade, em Frames of war: when is life grievable? (Quadros de guerra - quando a vida é passivel de luto? na tradução brasileira), Butler faz novos movimentos em relação ao seu percurso teórico. $\mathrm{O}$ abjeto, elemento fundamental para refletir como são constituídas as fronteiras que demarcam os corpos a partir de gênero, sexualidade, classe e raça, abre espaço para o aprofundamento do problema. Passará a ser importante pensar quais são as condições de possibilidade de uma vida ser reconhecida como vida, que para
7 A este respeito, importante mencionar as pesquisas de Berenice Bento acerca da violência contra a Palestina, tomando também a obra de Judith Butler como referência. Destacamos a exposição fotográfica Palestina meu amor (https://berenicebento.com/ palestina-meu-amor/).

8 Estamos privilegiando a interlocução de Butler com Goffman, mas consideramos necessário observar que há outras influências na maneira com que a filósofa vai se valer da ideia de quadro, enquadramento, moldura. O cinema de Trinh Minh-há e sua proposição de "enquadrar o enquadramento" será inspirador para a Butler de Quadros de guerra, onde também haverá um acento da sua abordagem pós-estruturalista em referência à filosofia de Jacques Derrida. Quando escreve La vérité en peinture (DERRIDA, 1978), o autor discute, em debate com a estética kantiana, a questão do parergon, elemento do quadro que faz ver que a borda, ou a moldura, e funciona como organizador das divisões dentro/fora, interior/ exterior. Para mais a respeito do parergon, permitimo-nos referir a Rodrigues, 2013. 
Butler vai depender não mais apenas de como um "eu" é constituído a partir da expulsão do "não-eu", mas como esta vida é enquadrada na experiência social.

Dito de outro modo, aos mecanismos psíquicos aos quais ela havia recorrido na leitura de Kristeva, somam-se elementos de crítica social que Butler encontra em Goffman. Vejamos como, na análise do sociólogo, as relações sociais são definidas não apenas a partir dos sistemas e das grandes estruturas, mas consideram principalmente as interações pessoais nas suas características microscópicas, de modo a pensar como cada indivíduo produz sua experiência pessoal a partir do que é capaz de "enquadrar" como real. Na citação, identificamos um movimento dialético próximo ao que já havíamos descrito em relação ao modo de constituição do abjeto: "Durante a ocorrência de qualquer atividade enquadrada de uma determinada maneira, é provável encontrar outro fluxo de outra atividade que é sistematicamente desatendida e tratada como fora de quadro, algo pelo qual não se deve mostrar nenhum interesse ou atenção" (Goffman, 2012, p. 264).

Aquilo que participa da formação do quadro depende dos elementos que ficarão fora do quadro, de tal modo que, ao enquadrar uma vida como inteligível, deste enquadramento se originará, também, a figura da vida ininteligível. Assim, quando Butler recorre a Goffman para pensar os "quadros de guerra”, faz pelo menos dois movimentos que nos interessam aqui. O primeiro, se alinhar ao conceito de Goffman, para quem a realidade nunca pode ser totalmente contida num quadro ou numa moldura. O segundo movimento da filósofa é ampliar as possibilidades do enquadramento, retomando o caráter polissêmico da expressão "to be framed". Ser enquadrado pode querer dizer ser emoldurado, posto dentro de um quadro ou moldura - e portanto estabelecer bordas e fronteira entre o dentro e fora -, assim como pode ser incriminar alguém por um ato ilícito ou "cair numa armação", armação aqui como outro significante que nos remete à noção de quadro e moldura.

A moldura nunca determinou realmente, de forma precisa, o que vemos, pensamentos, reconhecemos e apreendemos. Algo ultrapassa a moldura que atrapalha nosso senso de realidade; em outras palavras, algo acontece que não se ajusta à nossa compreensão estabelecida das coisas (Butler, 2015, p. 24).

A partir de Goffman, mas em deslocamento, Butler vai se interessar por aquilo que "escapa ao controle" (Butler, 2015, p. 25) do enquadramento, o que significa que o enquadramento "não é capaz de conter completamente o que transmite (...) e não mantém nada integralmente em um lugar" (Ibid., p. 26). Para fazer esse movimento, ela reforçará a relação entre "ser enquadrado" e ser "objeto de uma armação" (Ibid., p. 27), levando o conceito de enquadramento para uma posição mais dialética, na qual enquadrar e romper com o enquadramento são dois movimentos que caminham juntos. Assim, pensar a abjeção ou o resto é insuficiente porque passará a ser preciso pensar o que enquadra certas vidas como enlutáveis, inteligíveis, vivíveis. Enquadrar o enquadramento é outra maneira de dizer que a 
tarefa é pensar não apenas na precariedade de cada uma dessas formas de vida, mas pensar no que sustenta a condição de possibilidade de manter essas vidas precárias, enquadradas como humanas ou inumanas.

Se o humano é construído, Butler dirá, então também precisamos pensar no que se produz como resto, como rejeito: o inumano, o humanamente impensável. Esses abjetos excluídos circundam o humano e ameaçam a todo momento transpor suas fronteiras. Lembramos que esse exterior não é algo intrinsecamente além-limite, além-fronteiras. Não há ontologia do abjeto, ele é tão fruto do discurso quanto o sujeito da norma e só é passível de ser pensado em relação à norma de que se origina.

A questão de Butler gira em torno de como a materialização da norma no corpo produz um domínio de corpos abjetos, inumanos, que acabam por reforçar e solidificar o funcionamento da norma pela via da inclusão/exclusão. Mais do que isso, seu interesse está em articular o abjeto como lugar de agência política e ressignificação, ao se perguntar como esse abjeto pode desafiar os limites da norma de forma a expandi-la, fazendo com que se reescrevam os limites do que se qualifica como "corpos que importam, formas de viver que contam como 'vida', vidas que merecem proteção, vidas que merecem ser salvas, vidas que merecem ser enlutadas?” (Butler, 1993, p. 16).

Aqui, é importante observar que a condição de enlutável não é algo que se dê apenas quando a morte acontece, mas, bem ao contrário, ser enlutável é condição para que uma vida seja cuidada desde o seu nascimento, é condição para que uma vida seja inteligível como vida, seja enquadrada como cabível na heteronorma. Com isso, podemos retomar o debate sobre inteligibilidade nas relações de parentesco, como discutido por Butler na sua leitura para Antígona.

(...) as relações que têm sua legitimidade negada, ou que exigem novos termos de legitimação, não estão nem vivas nem mortas, figurando o não humano no limite do humano. E não é simplesmente que essas sejam relações impedidas de ser honradas ou de ser abertamente conhecidas e que, portanto, não podem ser publicamente enlutadas, mas essas relações envolvem pessoas que também estão restritas no seu luto, pessoas a quem é negado o poder de conferir legitimidade à perda (Butler, 2000, p. 79).

Legitimidade e direito ao luto estão aqui articulados como elementos que participam do enquadramento daqueles que podem ser admitidos na esfera pública, aqui entendida como campo de inteligibilidade, constituído no movimento de inclusão/exclusão já descrito na referência ao conceito de abjeção. Interessa então pensar como se dá a "morte social”, termo de Orlando Patterson retomado por Butler (2000, p. 73), condição de ser vivo, porém privado de todos os direitos que deveriam ser oferecidos a todo ser humano e como essa "morte social" é desigualmente distribuída às vidas carregadas de marcadores interseccionais de raça, classe, gênero, religião, local de nascimento, lugar de moradia etc.

Se a possibilidade de ser enlutada "é um pressuposto para toda vida que im- 
porta”, como argumenta Butler (2015, p. 32), a morte social carrega uma dupla impossibilidade: a de ter uma vida com valor e a de ter uma vida enlutável, recaindo sobre certos corpos a experiência permanente de ser apenas abjeto, nunca sujeito. Talvez por isso, em seu livro mais recente, The force of nonviolence (Butler, 2020), a filósofa considere que é preciso pensar o luto a partir da perspectiva de um processo contínuo, do qual participam marcadores como gênero, raça, classe, sexualidade. Esse enquadramento opera na distinção entre quem é ou não é uma vida a ser lembrada, enlutada, reconhecida e preservada. São formas de vida não integráveis, não inteligíveis, lançadas à categoria de excedente, de restos humanos elimináveis, para que certas formas de vida permaneçam detendo pelo menos dois privilégios: o poder de estabelecer que vidas humanas não serão consideradas humanas e o de serem inteligíveis como humanas.

\section{Considerações finais}

Neste artigo, buscamos estabelecer uma relação entre o conceito de abjeto como pensado por Butler no início dos anos 1990 e a ideia de vidas passíveis de ser enlutadas e vidas não enlutáveis, desenvolvida nos anos mais recentes da obra da autora. Observamos que em ambos os momentos teóricos, Butler se interessa por pensar a exclusão, assim como os limites que separam os sujeitos daqueles cujas vidas não importam, que são repudiados, rechaçados. Se o conceito de abjeção foi articulado pela filósofa para pensar as normas de gênero, a ideia de enlutável/ não-enlutável é proposta não somente para analisar a norma, mas também para criticá-la. Quando teoriza a categoria do luto, Butler expande seu estudo da norma, levando sua preocupação com a distinção entre inteligível e ininteligível para a esfera política num nível macro. Compreendemos que, em O clamor de Antígona, encontra-se o ponto da teoria de Butler em que luto e abjeção convergem. Sobretudo, entendemos que é o estatuto da inteligibilidade e da ininteligibilidade que se produz como articulador teórico em comum para as discussões quanto a ambos os conceitos.

Observamos que existem semelhanças entre a abjeção e o luto/luto impossível de certas vidas. Assim, sugerimos que a questão que acompanha Butler em sua obra parece se centrar no tema do que é inteligível ou ininteligível face a uma norma. Entendemos que esse assunto atravessa seus escritos, fazendo-se presente tanto quando trabalha o conceito de abjeto quanto quando se dedica a estudar os parâmetros que fazem com que uma vida "conte", seja enlutável. Se Butler passa a enfatizar menos o gênero e mais a violência (inclusive, de Estado), seu objeto de pesquisa parece-nos continuar sendo aqueles que são vistos como desimportantes, os sujeitos cujas vidas são excluídas e relegadas a uma zona inabitável, os rechaçados: vidas (e corpos) que não contam. 


\section{Referências}

BENTO, Berenice. O belo, o feio e o abjeto nos corpos femininos. Revista Sociedade e Estado, v. 36, n. 1, 2021.

BUTLER, Judith. Antigone's Claim: Kinship Between Life and Death. New York: Columbia University Press, 2000. [Ed. bras.: O clamor de Antígona: parentesco entre a vida e a morte. Trad. de André Checinel. Florianópolis: Editora da UFSC, 2014].

BUTLER, Judith. Bodies that matter. New York: Routledge, 1993.

BUTLER, Judith. Frames of War: when is life grievable? New York: Verso, 2009. [Ed. bras.: Quadros de Guerra: quando a vida é passível de luto? Trad. de Sérgio Lamarão e Arnaldo Cunha. Revisão técnica Carla Rodrigues. Rio de Janeiro: Civilização Brasileira, 2015].

BUTLER, Judith. Gender trouble. New York: Routledge, 1990.

BUTLER, Judith. Notes Toward a Performative Theory of Assembly. London: Harvard University Press, 2015. [Ed. bras.: Corpos em aliança e a política das ruas: notas sobre uma teoria performativa de assembleia. Trad. de Fernanda Miguens. Revisão técnica de Carla Rodrigues. Rio de Janeiro: Civilização Brasileira, 2018].

BUTLER, Judith. Precarious life: the power of mourning and violence. London: Verso, 2004. [Ed. bras.: Vida precária. Trad. de Andreas Lieber. Revisão técnica de Carla Rodrigues. Belo Horizonte: Autêntica, 2019].

BUTLER, Judith. The force of nonviolence: the ethical in the political. Londres: Verso, 2020.

DERRIDA, Jacques. La vérité en peinture. Paris: Flammarion, 1978.

DOUGLAS, Mary. Purity and danger: an analysis of the concepts of pollution and taboo. London; New York: Routledge, 2001 [1966].

FOUCAULT, Michel. História da sexualidade I: a vontade de saber. São Paulo: Graal, 2012 [1976].

GOFFMAN, Erving. Quadros da experiência social: uma perspectiva de análise. Trad. de Gentil Titton. Petrópolis: Vozes, 2012.

KOLNAI, Aurel. On disgust. Introduction by Barry Smith and Carolyn Korsmeyer. Chicago; La Salle: Open Court, 2004 [1929].

KRISTEVA, Julia. Pouvoirs de l'horreur. Approche de l'abjection. Paris: Editions du Seuil, 1980.

MBEMBE, Achille. Crítica da razão negra. Trad. de Sebastião Nascimento. São Paulo: N-1 Edições, 2018.

PORCHAT, Patrícia. Gênero, psicanálise e Judith Butler - do transexualismo à política. Tese [Doutorado em Psicologia Clínica] - Universidade de São Paulo, São Paulo, 2007.

PORCHAT, Patrícia. Um corpo para Judith Butler. Periódicus - Revista de estudos indisciplinares em gêneros e sexualidades, Salvador, v. 3, n. 1, p. 37-51, 2015.

RODRIGUES, Carla. A literatura entre Derrida e Lacan: dentro/fora das relações de poder. Viso: Cadernos de Estética Aplicada, v. 7, n. 13, p. 22-38, jan.-jun. 2013. 
RODRIGUES, Carla. O luto entre a clínica e a política: Judith Butler para além do gênero. Belo Horizonte: Autêntica, 2021.

RODRIGUES, Carla. Para além do gênero: anotações sobre a recepção da obra de Butler no Brasil. Revista Em construção, n. 5, p. 59-72, 2019.

RODRIGUES, Carla. Por uma filosofia política do luto. O que nos faz pensar, PUC-Rio, v. 29, n. 46, p. 58-73, 2020.

RUBIN, Gayle. Políticas do sexo. Trad. de Jamille Pinheiro Dias. São Paulo: Ubu, 2017.

STRATHERN, Marylin. O gênero e a dádiva. Trad. de André Villalobos. São Paulo: Editora Unicamp, 2009. 